\title{
Effect of Differential Thermal Drying Conditions on the Immunomodulatory Function of Ginger ${ }^{\mathbb{S}}$
}

\author{
Ji Su Lee ${ }^{1}$, Bomi Kim ${ }^{2}$, Jae Hwan Kim ${ }^{3}$, Minju Jeong ${ }^{3}$, Seokwon Lim ${ }^{2 *}$, and Sanguine Byun ${ }^{1 *}$ \\ ${ }^{1}$ Division of Bioengineering, Incheon National University, Incheon 22012, Republic of Korea \\ ${ }^{2}$ Department of Food Science and Technology and Center for Natural Sciences, Hoseo University, Asan 336-795, Republic of Korea \\ ${ }^{3}$ Department of Agricultural Biotechnology, Seoul National University, Seoul 08826, Republic of Korea
}

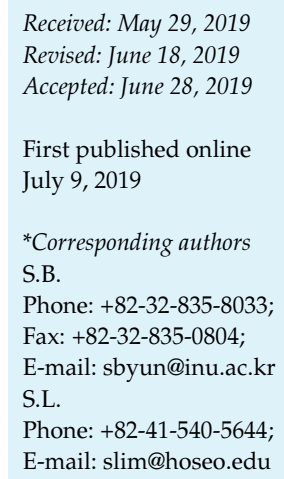

S upplementary data for this paper are available on-line only at http:/jmb.or.kr.

pISSN 1017-7825, eISSN 1738-8872

Copyright(C 2019 by

The Korean Society for Microbiology and Biotechnology

\begin{abstract}
Thermal drying is a common process used in the food industry for the modification of agricultural products. However, while various studies have investigated the alteration in physiochemical properties and chemical composition after drying, research focusing on the relationship between different dehydration conditions and bioactivity is scarce. In the current study, we prepared dried ginger under nine different conditions by varying the processing time and temperature and compared their immunomodulatory effects. Interestingly, depending on the drying condition, there were significant differences in the immunestimulating activity of the dried ginger samples. Gingers processed at $50^{\circ} \mathrm{C} 1 \mathrm{~h}$ displayed the strongest activation of macrophages measured by TNF- $\alpha$ and IL- 6 levels, whereas, freezedried or $70^{\circ} \mathrm{C}$ - and $90^{\circ} \mathrm{C}$-dried ginger showed little effect. Similar results were recapitulated in primary bone marrow-derived macrophages, further confirming that different dehydration conditions can cause significant differences in the immune-stimulating activity of ginger. Induction of ERK, p38, and JNK signaling was found to be the major underlying molecular mechanism responsible for the immunomodulatory effect of ginger. These results highlight the potential to improve the bioactivity of functional foods by selectively controlling processing conditions.
\end{abstract}

Keywords: Thermal drying, ginger, immunomodulation, MAPK pathway

\section{Introduction}

While food processing primarily functions to increase edibility, safety, and convenience of food, it can also cause a significant change in the bioactivity. There have been studies demonstrating the alteration in the chemical profile after processing of the raw material [1-3]. In the case of carrots, the amounts of $\beta$-carotene, polyphenols, and fibers differ among processed products like juice, concentrate, dried powder, and preserve, depending on their processing conditions [3]. Dried broccoli contains higher concentrations of flavonol glycosides such as quercetin 3-O-sophoroside, kampferol 3-O-sophoroside, and isoquercetin compared to fresh broccoli after cooking [4]. Another study reported that thermal dried tomatoes followed by blanching and freeze drying showed higher content of $\beta$-carotene and lycopene concentrations compared to other drying methods [2]. Heat treatment of cruciferous vegetables has been reported to induce degradation of certain isothiocyanates, including sulforaphane, sulforaphene, and phenethyl isothiocyanate $[5,6]$, whereas heating ginger may increase the content of certain bioactive compounds $[7,8]$. Because the chemical composition is the major factor determining the health-promoting effects of certain foods, elaborate design of food processing based on the chemical compositionfunction relationship can lead to the production of more potent functional food products $[9,10]$.

Ginger, a spice in food, has been used as traditional herbal medicine in many countries [11]. Studies have reported that ginger has anti-inflammatory and antioxidative effects as well as diverse health-promoting properties against cancer, degenerative disorders (arthritis, 
rheumatism, and Alzheimer's disease), cardiovascular disorders (atherosclerosis and hypertension), vomiting, and diabetes mellitus [12-20]. In addition, it has been reported that ginger can be effective in the control of a range of bacterial, viral, fungal and parasitic diseases in aquaculture and poultry farming [21, 22].

Drying is one of the conventional processing methods applied for preserving various types of agricultural products, such as ginger, by reducing the water content. It also makes a wide range of applications possible in food production by yielding favorable texture or altering nutrient contents. The drying process on ginger increases terpene hydrocarbons, reduces gingerols, and converts some monoterpene alcohols into their corresponding acetates [23]. Distinct methods of drying (e.g., thermal drying, freeze drying, microwave drying) can alter the components of the food. When the total phenolic content was compared after thermal drying and freeze drying of ginger, is was found that freeze-dried ginger had better antioxidant properties than thermal-dried ginger [24, 25]. Collectively, this evidence suggests that application of optimal processing methods on ginger could lead to an increase in specific bioactive nutrients as well as enhancement in certain health-improving functionality.

Macrophages are a heterogeneous group of cells that carry out distinct immuno-protective and -modulatory functions in various tissues. Increased proliferation and activation of macrophages can enhance immune function and thus promote health under certain conditions [26]. Under a steady and healthy state, macrophages regulate blood vessel permeability and phagocytose potentially harmful foreign agents as they cross into the tissue [26]. They are also involved in antigen presentation in various locations such as in the pancreatic islets of Langerhans and lung to initiate immune responses [27]. In tissues like the lung and testes, macrophages have immunosuppressive or anti-inflammatory properties, thereby preventing airway allergies or maintaining testicular immune privilege [28, 29]. In the spleen and lymph nodes, pathogen-exposed macrophages release large amounts of type I interferon during sepsis, which limits excessive adaptive immune responses [30]. In addition, it has been reported that the number of monocytes, which become macrophages, correlate with the recovery of the heart after myocardial infarction [31-33]. Microglia, the macrophages in the brain, play a crucial role in brain homeostasis as they actively survey and scavenge damaged parts [34]. Also, in cancer, reprogramming of tumor-associated macrophages toward M1-like macrophages is known to be an efficient way to promote tumor regression [35].

There have been multiple studies focusing on changes in the chemical profile of ginger after different drying methods [23, 24, 36, 37]. While the effect of drying on antioxidant and anti-microbial activity of ginger has been evaluated [24,37], research on the direct impact of dried ginger on immune-stimulatory activity is scarce. We hypothesized that the bioactivity can vary depending on the food processing conditions. In the current study, we have compared the immunomodulatory effect of ginger processed under various thermal drying conditions and examined the molecular mechanism responsible.

\section{Material and Methods}

\section{Materials}

Ginger (imported from China) was purchased from a local market. Antibodies for phospho-ERK, phospho-p38, phosphoJNK, and JNK were purchased from Cell Signaling Technology (MA, USA). SP600125 and antibodies for ERK, p38, and vinculin were obtained from Santa Cruz Biotechnology (USA). SB202190 and U0126 were purchased from Sigma-Aldrich (USA).

\section{Methods}

Preparation of dried ginger extract. Purchased ginger was washed and sliced into $1 \mathrm{~mm}$ of thickness just before drying. Ginger slices were dried under isothermal condition using both a lab-scale drying oven (OF-E, Jeio Tech, Korea) and an industrialscale drying machine (JW-1350ED, Jinwoo Electronic Devices, Korea). Dried ginger slices were pulverized using a multi-purpose blender (SMX-350SKH, Shinil, Korea), and then sifted using a sieve. The extraction was initiated by mixing $40 \mathrm{~g}$ of ginger powder with $500 \mathrm{ml}$ of $70 \%$ ethanol (No. 72, Korea) and then the mixture was incubated for $24 \mathrm{~h}$ at room temperature. The mixture was filtered using a $150 \mathrm{~mm}$ filter paper (Whatman grade 1, GE Healthcare, USA). Filtered extract was concentrated in drying oven at $65^{\circ} \mathrm{C}$ for 3 days and then lyophilized using a freeze dryer (FD8518, Ilshinbiobase, Korea).

Measurement of moisture content. The moisture content of the dried ginger samples was measured using a moisture analyzer (MB45, USA). Three samples obtained from different locations of the dryer were subjected to each measurement and repeated three times.

Cell culture. RAW264.7 murine macrophage cells were purchased from the Korean Cell Line Bank. Cells were cultured at $37^{\circ} \mathrm{C}$ in Dulbecco's modified Eagle's medium (DMEM, Corning, USA) supplemented with $10 \%$ fetal bovine serum (Gibco, USA) and $1 \%$ penicilin and streptomycin (Corning) in a humidified chamber with $5 \% \mathrm{CO}_{2}$.

Cell viability. Cell viability measurements were performed according to the manufacturer's instructions (CellTiter-Glo Luminescent Cell Viability Assay Kit, Promega, USA). Cells were 
seeded at $4 \times 10^{4}$ cells/well into white luminescence plates. Twenty-four hours after samples were added to the wells, the reagent was added to each well. The plate was subjected to an orbital shaker for $1 \mathrm{~min}$ and incubated at RT for $10 \mathrm{~min}$. Luminescence was measured using the Varioskan Lux Multimode Microplate Reader (Thermo Fisher Scientific, USA).

Enzyme-linked immunosorbent assay (ELISA). TNF- $\alpha$ and IL6 levels in the cell culture media were quantified by ELISA following the manufacture's instruction (R\&D Systems, USA). Next, 96-well microplates were incubated with the capture antibody overnight at RT. On the following day, plates were blocked with $1 \%$ BSA in PBS and washed with the wash buffer. Samples and standards were added and incubated for $2 \mathrm{~h}$. The plate was washed again, and allowed to incubate with the detection antibody for $2 \mathrm{~h}$. After washing, streptavidin-HRP was added and incubated for $20 \mathrm{~min}$. After a final wash, HRP/ substrate reaction was terminated with an equal volume of $2 \mathrm{~N}$ $\mathrm{H}_{2} \mathrm{SO}_{4}$ and the absorbance was measured on Varioskan Lux Multimode Microplate Reader (Thermo Fisher Scientific,) at 450$570 \mathrm{~nm}$.

Western blot analysis. Cells $\left(2.25 \times 10^{6}\right.$ cells $\left./ \mathrm{ml}\right)$ were rinsed, scraped off and collected with RIPA lysis buffer containing protease and phosphatase inhibitor (Sigma-Aldrich, USA). After centrifugation of the lysate, the supernatants were collected and quantified using the Pierce BCA Protein Assay Kit (Thermo Fisher Scientific). Proteins were separated by $10 \%$ SDS-PAGE and transferred to a nitrocellulose membrane (Bio-Rad). After blocking in 5\% skim milk in TBS containing 0.1\% Tween 20 (TBST) for $1 \mathrm{~h}$ the membrane was incubated with the corresponding antibody overnight at $4^{\circ} \mathrm{C}$. After washing with TBST, the membrane was incubated with HRP-conjugated secondary antibody for $1 \mathrm{~h}$ and membranes were visualized using a Western Lightning Plus-ECL (PerkinElmer, USA).

Isolation of bone marrow-derived macrophages. Primary macrophages were isolated from the bone marrow of female C57BL/6 mice, aged 6 weeks. The mice were purchased from Young Bio (Korea). Bone marrow cells were isolated from the femurs and tibias. Cells were differentiated for 6 days in DMEM/ F-12 (Corning, USA), containing fetal bovine serum, $1 \%$ penicillin and streptomycin, and $40 \mathrm{ng} / \mathrm{ml} \mathrm{M-CSF}$ (Peprotech, USA). The medium was replenished on the third day. All experimental protocols were approved by the Institutional Animal Care and Use Committee (SNU-170220-2-2) of Seoul National University, Seoul, Korea.

Statistical analysis. Statistical analysis was performed with GraphPad Prism 5.01 software, using one-way ANOVA test, and $p$ values of less than 0.05 were considered statistically significant.

\section{Results}

\section{Dehydration of Ginger under Various Thermal Drying Conditions}

To investigate the impact of differential processing
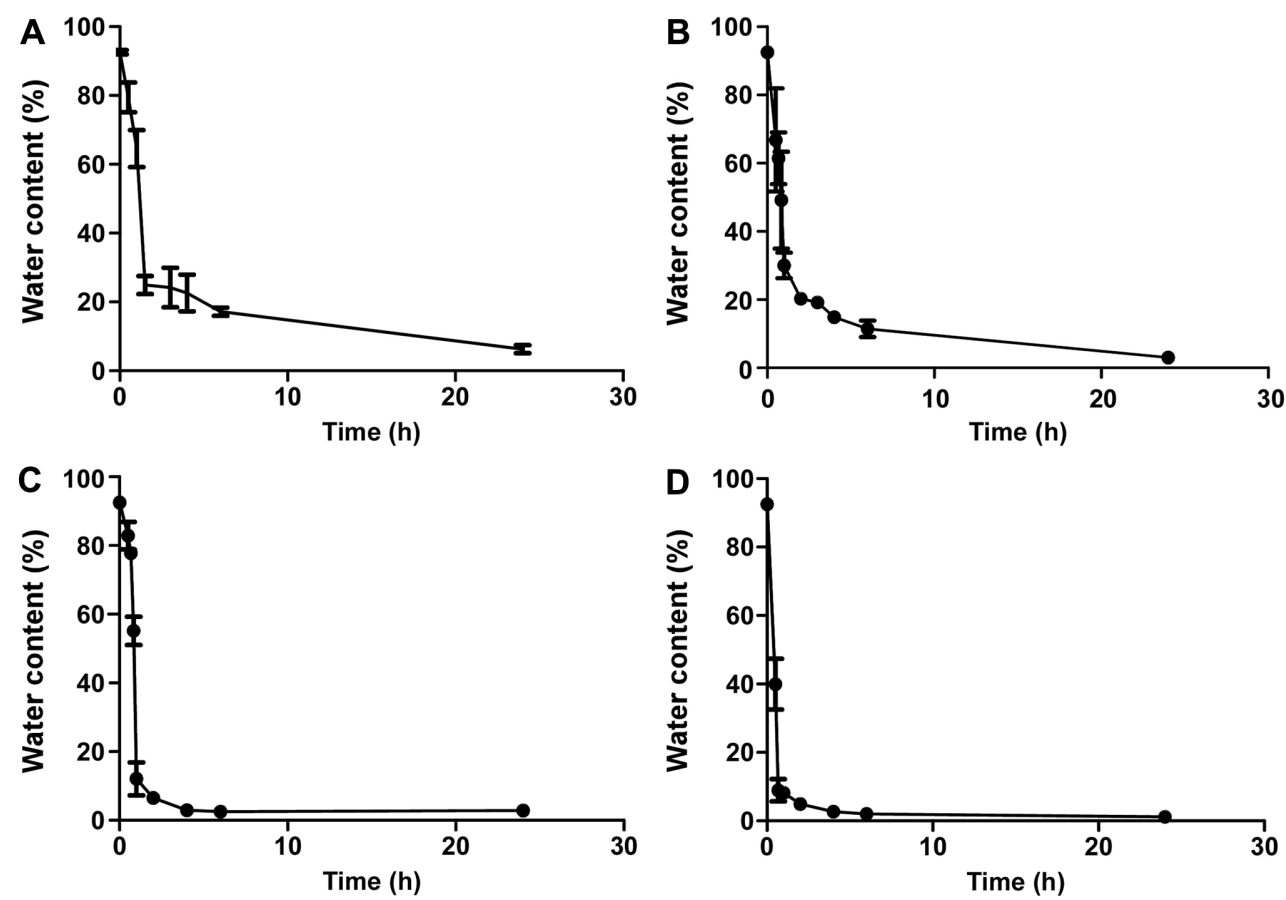

Fig. 1. Water content of ginger during isothermal dehydration process.

Water content was measured at various time points as indicated in the graph. Water content change during dehydration at $(\mathbf{A}) 30^{\circ} \mathrm{C},(\mathbf{B}) 50^{\circ} \mathrm{C},(\mathbf{C})$ $70^{\circ} \mathrm{C}$, (D) $90^{\circ} \mathrm{C}$. 
conditions on the bioactivity of ginger, we designed nine different thermal drying conditions through varying the processing temperature and time. We first examined the change in the moisture content of ginger under various temperatures $\left(30^{\circ} \mathrm{C}, 50^{\circ} \mathrm{C}, 70^{\circ} \mathrm{C}\right.$, and $\left.90^{\circ} \mathrm{C}\right)$. After drying for $24 \mathrm{~h}$ at $30^{\circ} \mathrm{C}, 50^{\circ} \mathrm{C}, 70^{\circ} \mathrm{C}$, and $90^{\circ} \mathrm{C}$, the moisture content of ginger dropped from $92.57 \%(\mathrm{w} / \mathrm{w})$ to $6.27,3.00,2.90$, and $1.17 \%(w / w)$, respectively (Fig. 1). During the drying process under isothermal conditions, a noticeable shift in the rate of moisture decline was observed at all temperatures (Fig. 1). Reduction in the rate of moisture decline after the rate shifting point indicates that the migration of water has decreased and thus ginger
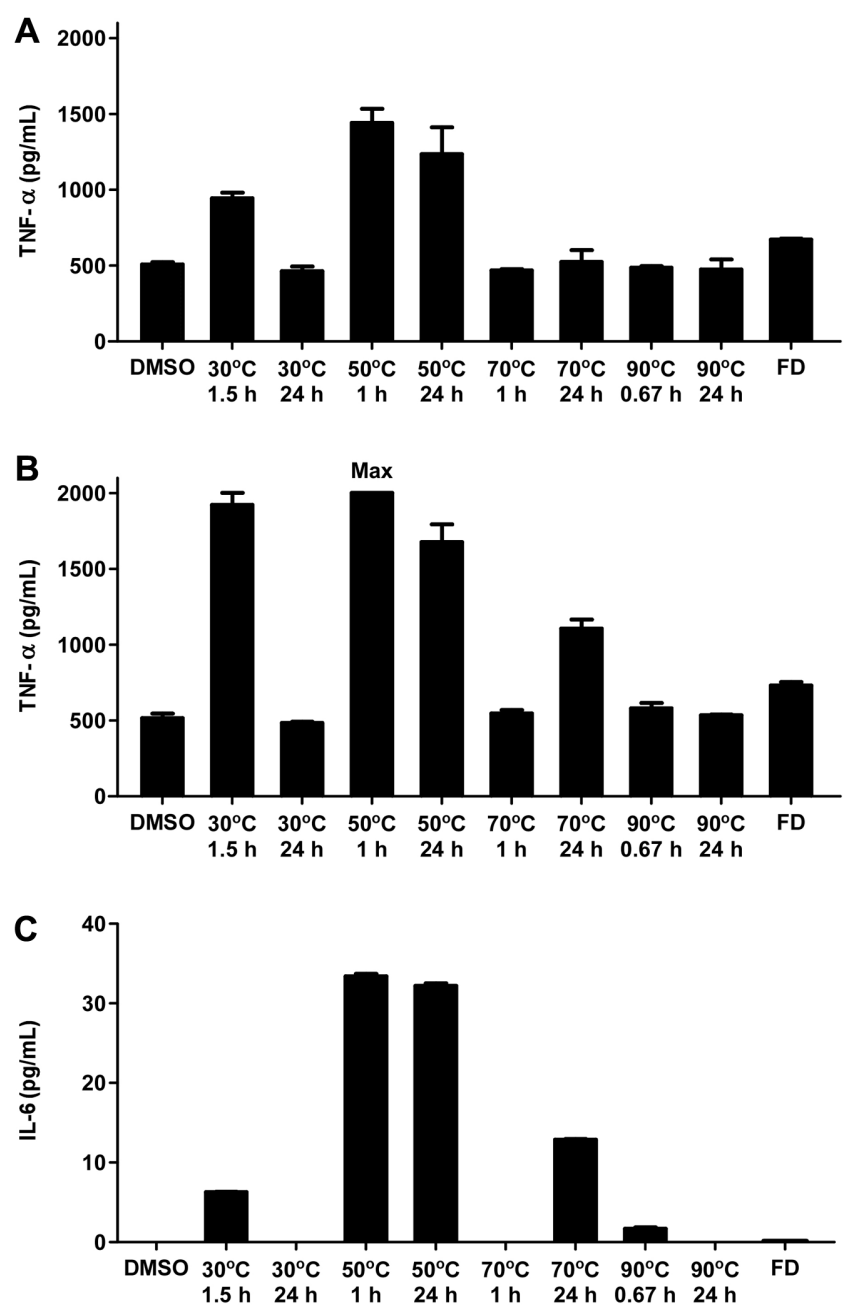

Fig. 2. Effect of various ginger samples on TNF- $\alpha$ and IL-6 production.

RAW264.7 cells were treated with ginger samples (A) $10 \mu \mathrm{g} / \mathrm{ml}$, (B) $20 \mu \mathrm{g} / \mathrm{ml}$, (C) $10 \mu \mathrm{g} / \mathrm{ml}$ and the media were collected after $18 \mathrm{~h}$ $(n=3)$. TNF- $\alpha$ and IL- 6 levels were measured as described in the Material and Methods section. All data are presented as mean \pm SD. components are likely to be exposed to stronger thermal stress. To explore the effect of thermal stress on potential changes in bioactivities, we selected samples at time points where rate shifts began and after $24 \mathrm{~h}$ of drying.

\section{Different Drying Conditions Cause Differential Immunomodulatory Activity of Ginger}

TNF- $\alpha$ and IL- 6 were used as biomarkers to compare the immunomodulatory function of various ginger extracts in RAW264.7 macrophages $[38,39]$. Conditions of $30^{\circ} \mathrm{C}-1.5 \mathrm{~h}$, $50^{\circ} \mathrm{C}-1 \mathrm{~h}, 50^{\circ} \mathrm{C}-24 \mathrm{~h}$, and $70^{\circ} \mathrm{C}-24 \mathrm{~h}$ displayed significant induction of TNF- $\alpha$ levels, whereas $30^{\circ} \mathrm{C}-24 \mathrm{~h}, 70^{\circ} \mathrm{C}-1 \mathrm{~h}$, $90^{\circ} \mathrm{C}-0.67 \mathrm{~h}, 90^{\circ} \mathrm{C}-24 \mathrm{~h}$, and FD showed little or no effect (Figs. 2A and 2B). Similarly, $50^{\circ} \mathrm{C}-1 \mathrm{~h}$ and $50^{\circ} \mathrm{C}-24 \mathrm{~h}$ also induced the highest levels of IL-6 compared to the other groups (Fig. 2C). The significant differences in their ability to promote cytokine production demonstrate that different thermal drying conditions used during dehydration can cause a major impact on the immunomodulatory functionality of ginger.

We next measured the endotoxin levels of each ginger extract used for the experiment to ensure that the results were not from contamination. The endotoxin levels were below detectable levels in the test samples (Table S1), proving that the immunomodulatory effect was not due to bacterial contamination. In addition, treatment of the ginger extracts did not cause any significant alteration in cell viability (Fig. 3), suggesting that the difference in the immunomodulatory effect was not a result of change in cell number or cytotoxicity.

ERK, p38, and JNK Pathways are Involved in the Immune-Stimulatory Activity of Ginger

In order to understand the molecular mechanism

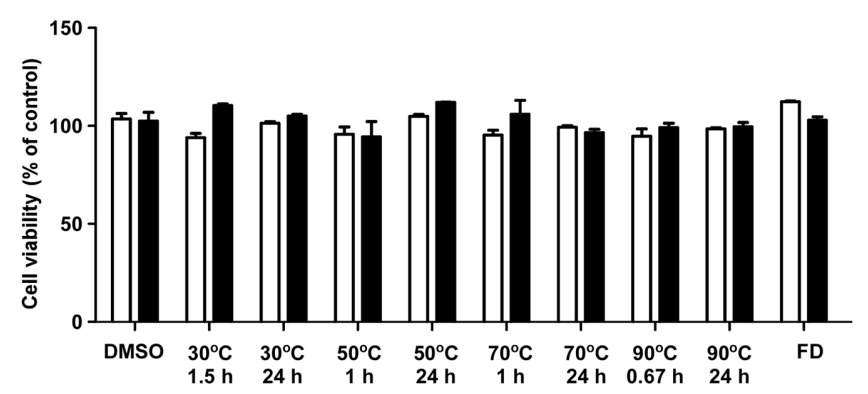

Fig. 3. Ginger samples do not exhibit cytotoxicity.

RAW264.7 cells were treated with ginger samples for $24 \mathrm{~h}(n=3)$. Cell viability was measured as described in the Material and Methods section. All data are presented as mean \pm SD. White bar indicates $10 \mu \mathrm{g} / \mathrm{ml}$ and black bar indicates $20 \mu \mathrm{g} / \mathrm{ml}$ of sample treatment. 
responsible for the differential bioactivity driven by thermal drying conditions, we investigated the major signaling pathways regulating macrophage activation. Extracellular signal-regulated kinases (ERK), c-Jun N-terminal kinases (JNK), and p38 have been well-known to play a major role

A

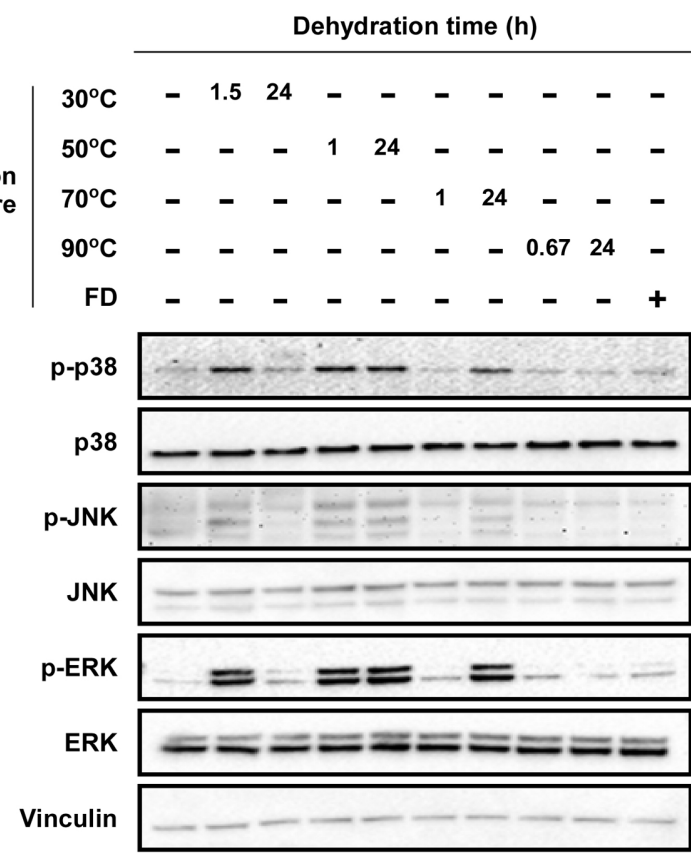

B

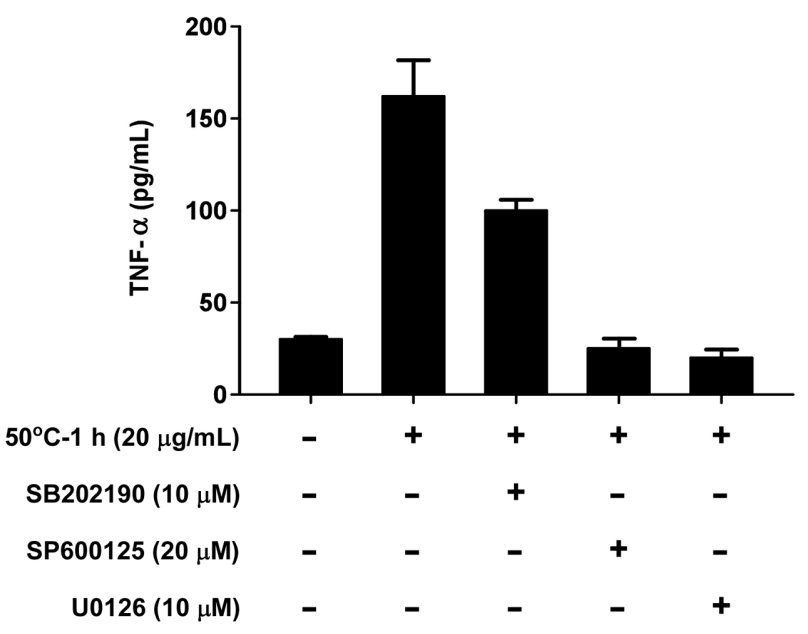

Fig. 4. Involvement of ERK, p38, and JNK in the immunomodulatory effect of ginger.

(A) Various ginger samples $(20 \mu \mathrm{g} / \mathrm{ml})$ were treated for $1 \mathrm{~h}$. Cells were lysed and the protein extracts were subjected to immunoblotting. Vinculin was used as a loading control. (B) Inhibitors of ERK, p38, and JNK were pre-treated $1 \mathrm{~h}$ prior to the addition of the ginger sample $50^{\circ} \mathrm{C}-1 \mathrm{~h}$. TNF- $\alpha$ levels were measured $6 \mathrm{~h}$ after treatment using the media. SB202190, p38 inhibitor; SP600125, JNK inhibitor; U0126, ERK inhibitor. All data are presented as mean \pm SD. in macrophage activation $[40,41]$. Interestingly, $30^{\circ} \mathrm{C}-1.5 \mathrm{~h}$, $50^{\circ} \mathrm{C}-1 \mathrm{~h}, 50^{\circ} \mathrm{C}-24 \mathrm{~h}$, and $70^{\circ} \mathrm{C}-24 \mathrm{~h}$, which stimulated the highest production of TNF- $\alpha$ levels, also exerted the strongest activation of p38, JNK, and ERK signaling pathways (Fig. 4A). On the other hand, treatment with $30^{\circ} \mathrm{C}-24 \mathrm{~h}, 70^{\circ} \mathrm{C}-1 \mathrm{~h}, 90^{\circ} \mathrm{C}-0.67 \mathrm{~h}, 90^{\circ} \mathrm{C}-24 \mathrm{~h}$, and FD did not cause any noticeable change in the phosphorylation levels of p38, JNK and ERK (Fig. 4A). The positive correlation between results from the TNF- $\alpha$ /IL- 6 expression and the signal activation shows that food processing condition can elicit major influences on the bioactivity of the product at the molecular level.

To further confirm the link between the alteration in signal transduction and immunomodulatory function of ginger extract, we co-treated p38, JNK, and ERK inhibitors with the ginger extract and assessed its effects on TNF- $\alpha$ production. As $50^{\circ} \mathrm{C}-1 \mathrm{~h}$ was the most potent ginger-drying condition in activating TNF- $\alpha$ and IL-6, as well as the signaling pathways, we selected $50^{\circ} \mathrm{C}-1 \mathrm{~h}$ to analyze the effect of specific inhibitors. Pre-treatment with either SP600125 (JNK inhibitor) or U0126 (ERK inhibitor) completely blocked the production of $50^{\circ} \mathrm{C}-1$ h-mediated TNF- $\alpha$ production, and SB202190 (p38 inhibitor) partially prevented TNF- $\alpha$ induction (Fig. 4B).

\section{Differential Immunomodulatory Activity of Ginger Can} Be Recapitulated in Primary Immune Cells

Immunological results generated from immortalized cell lines have been often reported to be not reproducible in physiological conditions. Thus, we next isolated bone marrow-derived macrophages (BMDMs) from mouse to

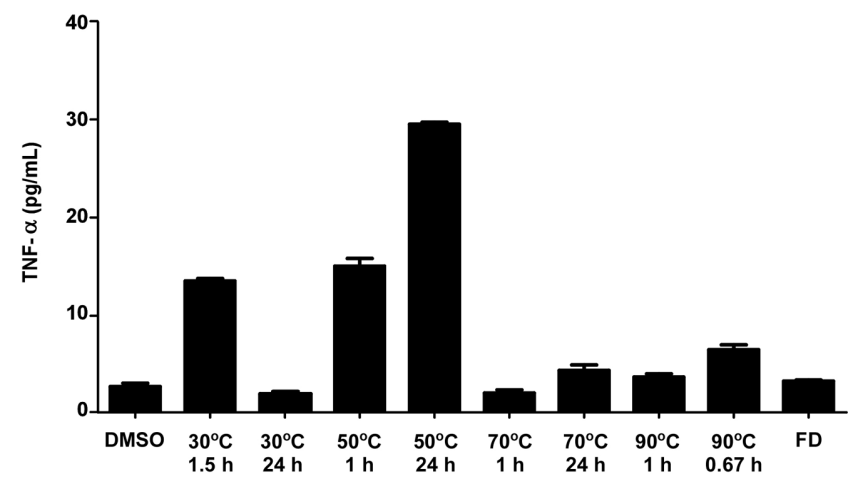

Fig. 5. Effect of various ginger samples on TNF- $\alpha$ production in BMDMs.

Primary BMDM cells were isolated from mouse and differentiated for 6 days. Media were collected for TNF- $\alpha$ analysis $24 \mathrm{~h}$ after the ginger samples $(10 \mu \mathrm{g} / \mathrm{ml})$ were treated $(n=3)$. All data are presented as mean $\pm \mathrm{SD}$. 
investigate whether the immunomodulatory function can be observed in primary immune cells. Treatment of $30^{\circ} \mathrm{C}$ $1.5 \mathrm{~h}, 50^{\circ} \mathrm{C}-1 \mathrm{~h}$, and $50^{\circ} \mathrm{C}-24 \mathrm{~h}$ led to a significant increase in TNF- $\alpha$ levels in BMDMs, whereas other groups displayed little or no effect, further confirming that different processing conditions can dramatically control the bioactivity of dried ginger even in ex vivo conditions (Fig. 5).

\section{Discussion}

Through comparing the immunomodulatory effects, we have found that different drying conditions can directly affect the bioactivity of dehydrated ginger. Depending on the processing temperature, the relative immune-stimulatory effect exhibited a pattern similar to a bell curve, where ginger dried at $50^{\circ} \mathrm{C}$ generated the strongest effect compared to that of other temperatures. Investigation of the molecular mechanism revealed that ERK, JNK, and p38 are mainly involved in ginger extract-driven macrophage activation. Interestingly, induction of the ERK, JNK, and p38 signaling pathways was also selectively observed only in some of the ginger samples and this pattern was consistent with the TNF- $\alpha /$ IL-6 production capability. ERK, JNK, and p38 have been known to function as a necessary condition for macrophage activation and proliferation [42]. Also, activation of ERK, JNK, and p38 pathways subsequently induces the activation of transcription factors including $\mathrm{NF}-\kappa \mathrm{B}$, to promote the production of cytokines such as TNF- $\alpha[42,43]$. Therefore, the immune-stimulating potency of ginger samples appears to be closely connected with their ability to upregulate phosphorylations of ERK, JNK, and p38.

It is likely that specific compounds have been preferentially modified only in certain thermal drying conditions during the dehydration process of ginger. Although there have been several studies examining the alteration in chemical composition of ginger after drying, most of the identified ginger components are known to exert immune-suppressive rather than immune-stimulatory activities [7, 15, 36, 37]. Based on our results, it can be postulated that the difference in drying conditions can induce strikingly diverse outcomes on the bioactivity of ginger. It appears that the immune-stimulatory effect of ginger dominates only when processed under low temperature-based drying conditions, such as $30^{\circ} \mathrm{C}-1.5 \mathrm{~h}$, $50^{\circ} \mathrm{C}-1 \mathrm{~h}$, and $50^{\circ} \mathrm{C}-24 \mathrm{~h}$. Since most of the ginger extracts commonly used are prepared either without heating or with drying at high temperatures (which corresponds to the FD or $70^{\circ} \mathrm{C}-1 \mathrm{~h}, 70^{\circ} \mathrm{C}-24 \mathrm{~h}, 90^{\circ} \mathrm{C}-0.67 \mathrm{~h}$, and $90^{\circ} \mathrm{C}-24 \mathrm{~h}$ conditions in our study), it may explain why most of the previous studies have reported immune-suppressive function of ginger. In our study, some samples that were dried for $24 \mathrm{~h}$ displayed relatively lower levels of macrophage activation compared to the ginger samples dried for a shorter period of time at the same temperature. Also, ginger dried at $50^{\circ} \mathrm{C}$ showed improved immunestimulator activity compared to ginger dried at $30^{\circ} \mathrm{C}$, but dehydration at higher temperatures (i.e. $70^{\circ} \mathrm{C}$ and $90^{\circ} \mathrm{C}$ ) did not increase the bioactivity. It could be possible that while a certain amount of heat energy is required to increase the content of immune-stimulatory compounds, long-term treatment or relatively high temperature conditions lead to a degradation of the compounds or inhibition of the generation process $[6,44]$.

In the current study, we have discovered that varied conditions of thermal drying can differentially impact the immunomodulatory function of ginger. Dehydrated ginger generated at specific conditions exhibited immunestimulatory effects which were attributed to their ability to activate ERK, JNK, and p38 pathways. Further studies on dissecting the relationship between food processing conditions and bioactivity will aid in developing accurate and personalized functional food products.

\section{Acknowledgments}

This work was funded by the National Research Foundation of Korea (NRF) grant funded by the Korean government (MSIP) (NRF-2017R1C1B1006072) to Sanguine Byun and was supported by the High Value-added Food Technology Development Program (118059-02), funded by iPET (Korea Institute of Planning and Evaluation for Technology in Food, Agriculture, Forestry and Fisheries) to Seokwon Lim.

\section{Conflict of Interest}

The authors have no financial conflicts of interest to declare.

\section{References}

1. Escudero-Lopez B, Cerrillo I, Gil-Izquierdo A, HorneroMendez D, Herrero-Martin G, Berna G, et al. 2016. Effect of thermal processing on the profile of bioactive compounds and antioxidant capacity of fermented orange juice. Int. J. Food. Sci. Nutr. 67: 779-788. 
2. Jorge A, Almeida DM, Canteri MHG, Sequinel T, Kubaski ET, Tebcherani SM, et al. 2014. Evaluation of the chemical composition and colour in long-life tomatoes (Lycopersicon esculentum Mill) dehydrated by combined drying methods. Int. J. Food Sci. Technol. 49: 2001-2007.

3. Sharma KD, Karki S, Thakur NS, Attri S. 2012. Chemical composition, functional properties and processing of carrot—a review. J. Food Sci. Technol. 49: 22-32.

4. Price KR, Casuscelli F, Colquhoun IJ, Rhodes MJC. 1998. Composition and content of flavonol glycosides in broccoli florets (Brassica olearacea) and their fate during cooking. J. Sci. Food Agric. 77: 468-472.

5. Byun S, Shin SH, Park J, Lim S, Lee E, Lee C, et al. 2016. Sulforaphene suppresses growth of colon cancer-derived tumors via induction of glutathione depletion and microtubule depolymerization. Mol. Nutr. Food Res. 60: 10681078.

6. Van Eylen D, Oey I, Hendrickx M, Van Loey A. 2007. Kinetics of the stability of broccoli (Brassica oleracea Cv. Italica) myrosinase and isothiocyanates in broccoli juice during pressure/temperature treatments. J. Agric. Food Chem. 55: 2163-2170.

7. Ali BH, Blunden G, Tanira MO, Nemmar A. 2008. Some phytochemical, pharmacological and toxicological properties of ginger (Zingiber officinale Roscoe): a review of recent research. Food Chem. Toxicol. 46: 409-420.

8. Byun S, Lim S, Mun JY, Kim KH, Ramadhar TR, Farrand L, et al. 2015. Identification of a Dual Inhibitor of Janus Kinase 2 (JAK2) and p70 Ribosomal S6 Kinase1 (S6K1) Pathways. J. Biol. Chem. 290: 23553-23562.

9. Abuajah CI, Ogbonna AC, Osuji CM. 2015. Functional components and medicinal properties of food: a review. J. Food Sci. Technol. 52: 2522-2529.

10. Ferreira SS, Passos CP, Madureira P, Vilanova M, Coimbra MA. 2015. Structure-function relationships of immunostimulatory polysaccharides: A review. Carbohydr. Polym. 132: 378-396.

11. Wang C-Z, Qi L-W, Yuan C-S. 2015. Cancer chemoprevention effects of ginger and its active constituents: potential for new drug discovery. Am. J. Chin. Med. 43: 1351-1363.

12. Azam F, Amer AM, Abulifa AR, Elzwawi MM. 2014. Ginger components as new leads for the design and development of novel multi-targeted anti-Alzheimer's drugs: a computational investigation. Drug Des., Dev. Ther. 8: 2045-2059.

13. Backon J. 1991. Ginger in preventing nausea and vomiting of pregnancy: a caveat due to its thromboxane synthetase activity and effect on testosterone binding. Eur. J. Obstet. Gynecol. Reprod. Biol. 42: 163-164.

14. Butt MS, Sultan MT. 2011. Ginger and its health claims: molecular aspects. Crit. Rev. Food Sci. Nutr. 51: 383-393.

15. Jafarzadeh A, Nemati M. 2018. Therapeutic potentials of ginger for treatment of Multiple sclerosis: A review with emphasis on its immunomodulatory, anti-inflammatory and anti-oxidative properties. J. Neuroimmunol. 324:54-75.
16. Li Y, Tran VH, Duke CC, Roufogalis BD. 2012. Preventive and protective properties of Zingiber officinale (ginger) in diabetes mellitus, diabetic complications, and associated lipid and other metabolic disorders: a brief review. Evid. Based Complement. Alternat. Med. 2012:516870.

17. Nicoll R, Henein MY. 2009. Ginger (Zingiber officinale Roscoe): a hot remedy for cardiovascular disease? Int. J. Cardiol. 131: 408-409.

18. Shukla Y, Singh M. 2007. Cancer preventive properties of ginger: a brief review. Food Chem. Toxicol. 45: 683-690.

19. Zeng GF, Zhang ZY, Lu L, Xiao DQ, Zong SH, He JM. 2013. Protective effects of ginger root extract on Alzheimer disease-induced behavioral dysfunction in rats. Rejuvenation Res. 16: 124-133.

20. Zheng W, Wang SY. 2001. Antioxidant activity and phenolic compounds in selected herbs. J. Agric. Food Chem. 49: 51655170 .

21. Shakya SR. 2015. Medicinal uses of ginger (Zingiber officinale Roscoe) improves growth and enhances immunity in aquaculture. Int. J. Chem. Stud. 3: 83-87.

22. Dhama K, Latheef SK, Mani S, Samad HA, Karthik K, Tiwari R, et al. 2015. Multiple beneficial applications and modes of action of herbs in poultry health and productionA review. Int. J. Phamacol. 11: 152-176.

23. Bartley JP, Jacobs AL. 2000. Effects of drying on flavour compounds in Australian-grown ginger (Zingiber officinale). J. Sci. Food Agric. 80: 209-215.

24. An K, Zhao D, Wang Z, Wu J, Xu Y, Xiao G. 2016. Comparison of different drying methods on Chinese ginger (Zingiber officinale Roscoe): changes in volatiles, chemical profile, antioxidant properties, and microstructure. Food Chem. 197: 1292-1300.

25. Gümüşay ÖA, Borazan AA, Ercal N, Demirkol O. 2015. Drying effects on the antioxidant properties of tomatoes and ginger. Food Chem. 173: 156-162.

26. Lapenna A, De Palma M, Lewis CE. 2018. Perivascular macrophages in health and disease. Nat. Rev. Immunol. 18: 689-702.

27. Shapouri-Moghaddam A, Mohammadian S, Vazini $H$, Taghadosi M, Esmaeili S-A, Mardani F, et al. 2018. Macrophage plasticity, polarization, and function in health and disease. J. Cell. Physiol. 233: 6425-6440.

28. Bedoret D, Wallemacq H, Marichal T, Desmet C, Calvo FQ, Henry E, et al. 2009. Lung interstitial macrophages alter dendritic cell functions to prevent airway allergy in mice. $J$. Clin. Invest. 119: 3723-3738.

29. Wang M, Fijak M, Hossain H, Markmann M, Nüsing RM, Lochnit G, et al. 2017. Characterization of the microenvironment of the testis that shapes the phenotype and function of testicular macrophages. J. Immunol. 198: 4327-4340.

30. Schwandt T, Schumak B, Gielen GH, Jüngerkes F, Schmidbauer P, Klocke K, et al. 2012. Expression of type I 
interferon by splenic macrophages suppresses adaptive immunity during sepsis. EMBO J. 31: 201-213.

31. Ruparelia N, Godec J, Lee R, Chai JT, Dall'Armellina E, McAndrew D, et al. 2015. Acute myocardial infarction activates distinct inflammation and proliferation pathways in circulating monocytes, prior to recruitment, and identified through conserved transcriptional responses in mice and humans. Eur. Heart J. 36: 1923-1934.

32. Tsujioka H, Imanishi T, Ikejima H, Kuroi A, Takarada S, Tanimoto $\mathrm{T}$, et al. 2009. Impact of heterogeneity of human peripheral blood monocyte subsets on myocardial salvage in patients with primary acute myocardial infarction. J. Am. Coll. Cardiol. 54: 130-138.

33. Kurihara T, Warr G, Loy J, Bravo R. 1997. Defects in macrophage recruitment and host defense in mice lacking the CCR2 chemokine receptor. J. Exp. Med. 186: 1757-1762.

34. Nimmerjahn A, Kirchhoff F, Helmchen F. 2005. Resting microglial cells are highly dynamic surveillants of brain parenchyma in vivo. Science 308: 1314-1318.

35. Genard G, Lucas S, Michiels C. 2017. Reprogramming of tumor-associated macrophages with anticancer therapies: radiotherapy versus chemo- and immunotherapies. Front. Immunol. 8:828.

36. Sangwan A, Kawatra A, Sehgal S. 2014. Nutritional composition of ginger powder prepared using various drying methods. J. Food Sci. Technol. 51: 2260-2262.

37. Ghasemzadeh A, Jaafar HZE, Baghdadi A, Tayebi-Meigooni A. 2018. Formation of 6-, 8- and 10-shogaol in ginger through application of different drying methods: altered antioxidant and antimicrobial activity. Molecules 23 (pii): E1646.

38. Martinez FO, Sica A, Mantovani A, Locati M. 2008. Macrophage activation and polarization. Front. Biosci. 13: 453-461.

39. Wynn TA, Chawla A, Pollard JW. 2013. Macrophage biology in development, homeostasis and disease. Nature 496: 445455.

40. Mosser DM, Edwards JP. 2008. Exploring the full spectrum of macrophage activation. Nat. Rev. Immunol. 8: 958-969.

41. Rao KM. 2001. MAP kinase activation in macrophages. J. Leukocyte. Biol. 69: 3-10.

42. Lloberas J, Valverde-Estrella L, Tur J, Vico T, Celada A. 2016. Mitogen-activated protein kinases and mitogen kinase phosphatase 1: a critical interplay in macrophage biology. Front. Mol. Biosci. 3: 28.

43. Campbell J, Ciesielski CJ, Hunt AE, Horwood NJ, Beech JT, Hayes LA, et al. 2004. A novel mechanism for TNF-alpha regulation by p38 MAPK: involvement of NF-kappa B with implications for therapy in rheumatoid arthritis. J. Immunol. 173: 6928-6937.

44. Jung MY, Lee MK, Park HJ, Oh EB, Shin JY, Park JS et al, 2017. Heat-induced conversion of gingerols to shogaols in ginger as affected by heat type (dry or moist heat), sample type (fresh or dried), temperature and time. Food Sci. Biotechnol. 27: 687-693. 